\title{
A Comparative Study to Evaluate Accuracy on Canopy Height and Density Using UAV, ALS, and Fieldwork
}

\author{
Cheonggil Jin ${ }^{1}$, Che-young Oh ${ }^{2}$, Sanghyun Shin ${ }^{1}$, Nkwain Wilfred Njungwi ${ }^{1}$ \\ and Chuluong Choi ${ }^{1, *}$ \\ 1 Division of Earth Environmental System Science (Major of Spatial Information Engineering), \\ Pukyong National University, Busan 49513, Korea; cgjin@pukyong.ac.kr (C.J.); cutie_77@naver.com (S.S.); \\ nnjungwi@gmail.com (N.W.N.) \\ 2 Hydrographic Technology Research Center, Korea Hydrography and Research Association, Seoul 08590, \\ Korea; ocy@khra.kr \\ * Correspondence: cuchoi@pknu.ac.kr; Tel.: +82-51-629-6655
}

Received: 30 December 2019; Accepted: 19 February 2020; Published: 22 February 2020

check for updates

\begin{abstract}
Accurate measurement of the tree height and canopy cover density is important for forest biomass and management. Recently, Light Detection and Ranging (LIDAR) and Unmanned Aerial Vehicle (UAV) images have been used to estimate the tree height and canopy cover density for a forest stands. More so, UAV systems with autopilot functions, affordable Global Navigation Satellite System (GNSS) and Inertial Measurement Unit (IMU) have created new possibilities, aided by available photogrammetric programs. In this study, we investigated the possibility of data collection methods using an Aerial LIDAR Scanner (ALS) and an UAV together with a fieldworks to evaluate accurate the tree standard metrics in Singyeri, Gyeongjusi, and Gyeongsangbukdo province. The derived metrics via statistical analyses of the ALS and UAV data and validated by field measurements were compared to a published forest type map (scale 1:5000) by the Korea Forest Service; geared towards improving the forest attributes. We collected data and analyzed and compared them with existent the forest type map produced from an aerial photographs and a digital stereo plotter. The ALS data of around 19.5 points $\cdot \mathrm{m}^{-2}$ were collected by an airplane, then processed and classified using the LAStools; while about 362 images of the UAV were processed via Structure from Motion algorithm in the Agisoft Metashape Pro. Thus, we calculated the metrics using the point clouds of both an ALS and an UAV, and then verified their similarity. The fieldwork was manually done on 110 sampled trees. Calculated heights of the UAV were 3.8 5.8 m greater than those for the ALS; and when correlated with the fieldwork, the UAV data overestimated, while the maximum height of the ALS data was more accurate. For the canopy cover, the ALS computed canopy cover was 10\% 30\% less than that of the UAV. However, the canopy cover above $2 \mathrm{~m}$ by an UAV was the best measurement for a forest canopy. Therefore, these results assert that the examined techniques are robust and can significantly complement methods of the conventional data acquisition for the forest type map.
\end{abstract}

Keywords: Light Detection and Ranging; Tree height; Aerial LIDAR Scanner; Unmanned Aerial Vehicle; Structure from Motion; Forest type map; Canopy cover

\section{Introduction}

More than $63 \%$ of South Korea is a forest zone. As such, these resources are both environmentally and economically important to the country. The total forested area peaked at 6750 kilo hectares in 1961, and has continuously declined since to 6335 kilo hectares in 2017 [1].

The Korea Forest Service in South Korea started to create the forest type map that includes tree attribute data to aid efficient forest management. The first forest type maps were made between 2008 
and 2012, and the border zone was added in 2013, so that the whole country is mapped. After that, the forest type map's accuracy improved from 2014 to 2019. The Korean forest type map describes the distribution of the tree attributes such as diameter at breast height, tree age, tree height, and canopy cover density. The forest type map produced by the Government of South Korea is among the main national thematic maps, which include: Topographic, soil, and geology maps.

It is important to evaluate the accuracies of the forest type map produced at the national level [2]. A tree height is measurable in accessible areas such as a roads and graveyards. But this is difficult in a dense forest. A diameter at breast height and a tree age can both be obtained from woodchip statistics established during a forest exploitation. Considering all of these factors, and the fact that the forest type map has about 150 200 polygons per the forest type map (scale 1:5000), it can be difficult to judge the overall accuracy of the forest type map. Alternatives such as an airborne laser scanning and a terrestrial LIDAR scanning can improve the evaluation of the forest metrics [3]. But they are time consuming and expensive.

Recently, a tree height and a diameter at breast height have been measured using a small Light Detection and Ranging (LIDAR) unit mounted on an UAV [4], and a rigorous survey using only an ALS and a fieldwork data has been conducted [5]. Having estimated tree height using an ALS in a tropical rainforest [6], individual trees were detected using an ALS [7], and tree height and diameter at breast height have been measured using an ALS [8]. In other work, the high resolution images have been acquired using an UAV and automatic 3D photographic reconstruction methods have been used to determine a tree height $[9,10]$. In addition, a researchers have compared the suitability of the UAV photography and ALS point clouds for a forestry applications [11], and have compared RIEGL RiCOPTER and a terrestrial LIDAR scanning measurements of the canopy height and diameter at breast height [4].

In this study, we investigated an ALS and an UAV data collection methods and compared them to the standard metrics (a tree height and a canopy cover density based on the class definition in the Forest Type Map of South Korea), a diameter at breast height, a tree age in the field; used statistical analyses to validate and assess an ALS and an UAV data; and then compared with the fieldwork likewise the forest type map.

\section{Research Area and Methodology}

\subsection{Study Area}

The study area is located in Singyeri, Gyeongjusi, Gyeongsangbukdo province as Figure 1, South Korea (N 35 46 $30^{\prime \prime}$, E $129^{\circ} 20^{\prime} 40^{\prime \prime}$ ). This research site elevation ranges from 198 to $384 \mathrm{~m}$ above sea level and the topography is primarily steep hills. This region typically constitutes a variety tree population. Around 29.8\% Pinus koraiensis (PK) grow at high altitudes and are distributed across Korea, Japan, Northeastern China, and far Eastern Russia. In China, these trees are referred to as the Silla pines and Japanese refer to them as the Korean pines. The Pinus densiflora (PD) $28.4 \%$ is the most common conifer in South Korea, and is found across the country in artificial and natural forests. In this study, it was the only naturally occurring tree as other trees were in artificial forests. About $5.1 \%$ Larix kaempferi (LL) is a deciduous needled tree that originated in Japan, and is the most commonly planted tree in South Korea. It grows best in cold climates, and is found in the Kuma Highlands of North Korea. The Abies holophylla (AH) $3.8 \%$ is a typical Korean conifer that grows in high altitude mountainous areas with low temperatures. It has a straight, long trunk, and is a native Korean species that grows in groups of hundreds or thousands. Additionally, $19.1 \%$ etc. broadleaf (EB), $4.6 \%$ mixed forest (MM), 2.1\% Populous (PO), 0.5\% Quercus acutissima (QA), 2.4\% Quercus mongolica (QM), 1.2\% Etc. Quercus (QQ), and 3.0\% Quercus variabilis (QV) are irregularly distributed all over Korea. However, in the fieldwork only PK, PD, LL, and AH species were sampled and measured. This species is the dominant species order excluding the mixed forest (MM, EB). In the mixed forest it is difficult to find a dominant species, so we did not choose it. 


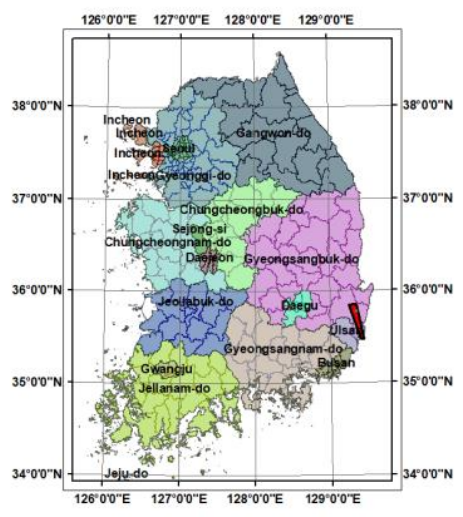

(a)

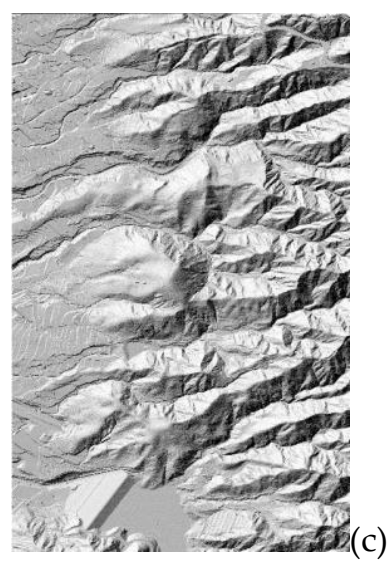

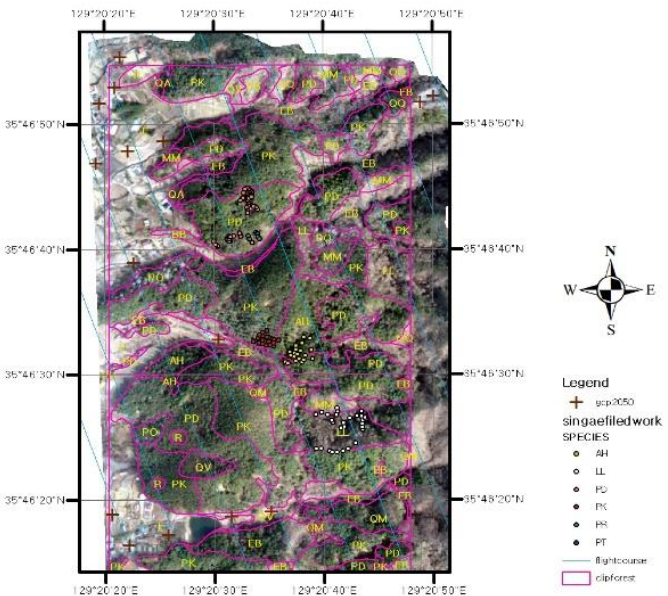

(b)

Figure 1. (a) The location of the study area marked on the forest type map, (b) The ground control points and the fieldwork points on an Unmanned Aerial Vehicle (UAV) orthoimages, (c) Aerial LIDAR Scanner's (ALS's) Digital Elevation Models hillshade (d) LL photo in a fieldwork, (e) Abies holophylla $(\mathrm{AH})$ photo in a fieldwork.

\subsection{Aerial LIDAR and Data Processing}

This research flowchart is shown in Figure 2. It is important to be able to measure the properties of a single tree in a forest. LIDAR and an ALS can estimate the dimensions of the trees [4,12]. ALS data are commonly collected using an airplane, thereby covering a large area. Data density is typically 1-10 point $\cdot \mathrm{m}^{-2}$, and is determined by the flight altitude and scanner configuration [4]. High resolution ALS data with more than 10 point $\cdot \mathrm{m}^{-2}$ can be used to detect and measure the height, crown diameter, and position of the trees as validated by the field measurements [13]. The ALS data used in this study were collected between 4 and 25 January 2018, using a Leica ALS60 to measure an area of about 266 kilo hectares from an altitude of 1700 2325 m above sea level, and about $1500 \mathrm{~m}$ above ground level. The flight speed was in the range of $211 \sim 228 \mathrm{~km} \cdot \mathrm{hour}^{-1}$, the flight course interval was $110 \mathrm{~m}$, the pulse return was 1 4 point and the scan angle was in the range $-11 \sim 14^{\circ}$ with a point density of 19.5 point $\cdot \mathrm{m}^{-2}$ as shown in Table 1. A Terrascan and Microstation (Terrasolid Co.) program was used for a basic LIDAR data processing. 
Table 1. Aerial Light Detection and Ranging (LIDAR) Scanner and UAV point clouds statistic.

\begin{tabular}{|c|c|c|c|c|c|c|c|c|c|c|}
\hline \multirow[t]{2}{*}{ Item } & \multicolumn{2}{|c|}{ Point Count } & \multicolumn{2}{|c|}{ Percent (\%) } & \multicolumn{2}{|c|}{$\mathrm{Z}$ Min (m) } & \multicolumn{2}{|c|}{$\mathrm{Z} \operatorname{Max}(\mathrm{m})$} & \multicolumn{2}{|c|}{$\begin{array}{c}\text { Density } \\
\left(\text { point } \cdot \mathrm{m}^{-2}\right)\end{array}$} \\
\hline & ALS & UAV & ALS & UAV & ALS & UAV & ALS & UAV & ALS & UAV \\
\hline $1 \mathrm{st}$ & $12,447,163$ & $16,031,828$ & 67.59 & 100.00 & 198.0 & 198.6 & 384.1 & 384.3 & 13.2 & 17.0 \\
\hline 2 nd & $5,094,477$ & & 27.66 & & 198.0 & & 380.2 & & 5.4 & \\
\hline $3 r d$ & 830,550 & & 4.51 & & 198.1 & & 374.4 & & 0.9 & \\
\hline 4 th & 42,842 & & 0.23 & & 202.1 & & 367.7 & & 0.0 & \\
\hline Single & $7,355,064$ & $16,031,828$ & 39.94 & 100.00 & 198.0 & 198.6 & 383.3 & 384.3 & 7.8 & 17.0 \\
\hline All & $18,415,032$ & $16,031,828$ & 100.00 & 100.00 & 198.0 & 198.6 & 384.1 & 384.3 & 19.5 & 17.0 \\
\hline
\end{tabular}

UAV(Unmanned aerial vehicle)

ALS(Aerial LIDAR Scanner)

\begin{tabular}{|c|c|c|}
\hline Digital image from UAV & \multirow{2}{*}{$\begin{array}{l}\text { GCP by Surveyor GNSS } \\
\text { (Global Navigation } \\
\text { Satellite System) }\end{array}$} & Aerial Lidar data from airplane \\
\hline Photo alignment / dense cloud & & $\begin{array}{l}\text { Strip alignment by GCP } \\
\text { (ground control points) }\end{array}$ \\
\hline LAS data Classification & $\begin{array}{l}\text { Extract Ground LAS(Lidar } \\
\text { cloud point data) }\end{array}$ & LAS data Classification \\
\hline Merge LAS \& ALS Ground LAS & \multirow[b]{3}{*}{ comparision } & \\
\hline Tree height normalization & & Tree height normalization \\
\hline $\begin{array}{l}\text { Canopy density \& Tree height by } \\
\text { percentile }\end{array}$ & & $\begin{array}{c}\text { Canopy density \& Tree height by } \\
\text { percentile }\end{array}$ \\
\hline
\end{tabular}

Tree DBH(Diameter at Breast Height), Age, Height and
Canopy Density by Fieldwork
comparison
$\stackrel{\text { Field data validation \& assessment }}{\text { Forest type map }}$ comparison
\[ \text { Forest Type map validation \& assessment comparison } \]

Figure 2. Research flowchart. 
For strip alignment, we surveyed 57 ground control points (GCPs) with Sokkia GRX2. According to a Global Navigation Satellite System (GNSS) the accuracy was $10 \mathrm{~mm}+1 \mathrm{ppm}$ (horizontal) and $15 \mathrm{~mm}+1 \mathrm{ppm}$ (vertical). This accuracy depends on the number of satellites visible, the position of dilution of precision (PDOP), multipath signal errors, and the baseline length. The resulting positional accuracy was about $2-5 \mathrm{~cm}$. BayesStripalign 2.1 was used to calculate the vertical difference between overlapped scan swath [14]. The point cloud collection technique is resistant to variation in vegetation, mismatched surfaces, and natural differences due to perspective. The optimal conditions were automatically calculated from the relative displacement using a rigorous model and Bayesian interference [9].

After alignment, the root mean square error was $3.5 \mathrm{~cm}$ and the $95 \%$ confidence interval $\left(\mathrm{CI}_{95}\right)$ was $6.9 \mathrm{~cm}$. LAS data processing and classification was performed using LAStools [15]. LAStools are capable of classifying, tiling, converting, filtering, rastering, triangulating, contouring, and clipping LIDAR data [15].

The Lasclassify tool available in LAStools is suitable to classify buildings and tall vegetation (i.e., trees). Using ALS and LAStools, the area was determined to be $37.61 \%$ ground with 7.81 point $\cdot \mathrm{m}^{-2}$, $55.51 \%$ vegetation with 10.8 point $\cdot \mathrm{m}^{-2}$, and $6.88 \%$ other with 1.4 point $\cdot \mathrm{m}^{-2}$. The tree height was normalized using the Lasheight function of LAStools, which computes the tree height of each point above the ground. This process assumes that the ground has been accurately mapped, and a triangular irregular networks (TIN) have been constructed. Tree height normalized LIDAR point clouds is then used to calculate forest metrics such as the canopy cover density, tree height percentiles, mean, minimum, and maximum. The standard input metrics are defined in Table 2.

Table 2. Standard tree metrics [16] collected using UAV and ALS.

\begin{tabular}{|c|c|c|c|c|c|}
\hline \multicolumn{3}{|c|}{ Tree Height (Above 2m from Ground) } & \multicolumn{3}{|c|}{ Canopy Cover Density (Above $2 \mathrm{~m}$ from Ground) } \\
\hline \multicolumn{2}{|c|}{ Standard Metric } & Description & \multicolumn{2}{|c|}{ Standard Metric } & Description \\
\hline \multirow{4}{*}{ Percentiles } & $\mathrm{H}_{25}$ & Above 25th height & \multirow{3}{*}{ Percentiles } & $\mathrm{CC}_{3}$ & Above 25 th canopy cover \\
\hline & $\mathrm{H}_{50}$ & Above 50th height & & $\mathrm{CC}_{5}$ & Above 50th canopy cover \\
\hline & $\mathrm{H}_{75}$ & Above 75th height & & $\mathrm{CC}_{7}$ & Above 75 th canopy cover \\
\hline & $\mathrm{H}_{95}$ & Above 95th height & \multirow[b]{2}{*}{$\mathrm{CC}_{2 \mathrm{~m}}$} & $\mathrm{CC}_{9}$ & Above 95 th canopy cover \\
\hline $\mathrm{H}_{\mathrm{m}}$ & & Max. height & & & Canopy cover above $2 \mathrm{~m}$ \\
\hline $\mathrm{H}_{\mathrm{n}}$ & & Mean height & $\mathrm{CC}_{\text {mean }}$ & & $\begin{array}{c}\text { Canopy cover above mean } \\
\text { height }\end{array}$ \\
\hline
\end{tabular}

\subsection{UAV Digital Image and Data Processing}

In recent years, UAV systems with autopilot functions, low cost GNSS devices, and inertial sensors have created new possibilities for remote measurement applications using commercially available photogrammetric programs [9]. The UAV used here had a central processing unit (CPU) with an integrated Attitude and Heading Reference System (AHRS) based on an L1 GNSS and Inertial Measurement Unit (IMU: accelerometers, gyroscopes, and a magnetometer) [17]. High resolution imagery can be used to determine a tree height and a crown diameter [10], and a LAS data files can be produced using Structure From Motion photogrammetry data exploration and processing [18].

The digital UAV images used in this study were collected on 11 April 2019 using a DJI Inspire 2 and Zenmuse X4S camera that covered the whole study area over $115 \mathrm{ha}$, at an altitude of $150 \mathrm{~m}$ above the takeoff site (Figure. 1b). The flight speed was $18 \mathrm{~km} \cdot \mathrm{hour}^{-1}$, and the overlap and sidelap of the flight were $80 \%$ and $70 \%$, respectively.

The camera settings were manual during the flight to ensure constant radiometric imagery conditions [19]. The focal length was $8.8 \mathrm{~mm}$ ( $35 \mathrm{~mm}$ converted into $24 \mathrm{~mm}$ ), the aperture was $\mathrm{f} / 4.5$, and a sensitivity of ISO 100 was used. The ground sample distance (GSD) was set to $8.95 \mathrm{~cm} /$ pixel and 362 images were captured so that the average point canopy cover density was consistent for comparison between UAV and aerial LIDAR data. The average point density was 17 point $\cdot \mathrm{m}^{-2}$ (see Table 1 ). The 15 GCPs within the study area were surveyed and located by Sokkia GRX2 RTK, and the root mean square 
error of their measured positions was $6.2 \mathrm{~cm}, 8.8 \mathrm{~cm}$, and $22.2 \mathrm{~cm}$ in the $\mathrm{x}, \mathrm{y}$, and z-axes, respectively. The root mean square error of the point cloud reprojection error was 0.822 pixel.

Agisoft Metashape is an image-based 3D modeling program for still images that can built the estimated camera positions and pictures themselves. Images were processed using the Structure from Motion and bundle adjustment (this minimized the reprojection error in the units of tie point) algorithm available in Agisoft Metashape Pro (v1.5.2) [18]. Alignment photographs were captured, the camera was calibrated, a dense point cloud was built, and the ground was classified and exported to a UAV LAS data file. However, the UAV captured limited ground data. Accurate calculation of the tree height of each point above the ground requires ground points that have been classified to enable the construction of a ground TIN. Digital aerial photogrammetry image processing was used to merge the UAV and ALS data and to normalize the tree height. The point clouds were normalized to the ALS LAS data so that the tree height relative to ground could be derived and normalized.

\subsection{Field Forest Measurement}

The fieldwork was conducted on 11 and 12 May 2019. A Haglof vertex laser, Haglof increment borer, and diameter tape were used to measure the tree height, tree age, and diameter at breast height respectively. This measurement was done at each of the four locations identified with a GNSS receiver (GRX 2, Sokkia, Japan) device and the trees considered had the diameter at breast height greater than $13 \mathrm{~cm}$ [20]. However, fieldwork is expensive and time consuming, and taking measurements in high density forests is challenging. Thus, we identified four locations in the research area with easy accessibility and trees near open space.

During the fieldwork, we preferred to exploit the areas demarcated by the forest type map researcher over 5 years ago. A total of 110 trees were measured: 20 from AH, 30 from LL, 40 from PD, and 20 from PK. Indirect methods were used to measure tree height in the forest. Typically an angle between the base and top of a tree, and the horizontal distance to the tree base from the measurement point were used to estimate the tree height according to basic trigonometric formulae [5].

A Haglof vertex laser (VL400, Haglof inc., Sweden) was used for tree height measurement, which had an ultrasonic accuracy of $\pm 1 \%$ over $20 \mathrm{~m}$, and a laser accuracy of $\pm 0.4 \mathrm{~m}$ in $100 \mathrm{~m}$. The laser was used in low density artificial forests, while the ultrasonic function was used in high density natural areas.

Tree age was measured 110 trees using a Haglof increment borer, which extracted a bore with diameter $5.15 \mathrm{~mm}$, and maximum length $40 \mathrm{~cm}$, and diameter at breast height was measured 110 trees using diameter tape. Canopy cover density measuring was an impracticable task and we used observation with the naked eye method near mountain road. The forest type map of South Korea has only 3 classes. But, in the forest map, canopy cover density estimated by researcher eye in digital stereo plotter.

\subsection{Tree Standard Metrics for UAV, ALS, and Class Definition in the Forest Type Map of South Korea.}

ALS and UAV image LAS files were compared using two sets of metrics calculated from the UAV images and ALS point cloud. The LAS point clouds were calculated by subtracting the ground elevation from the cloud points [21], and LAStools were used to compute standard tree metrics [14]. The metrics were calculated using both the ALS and UAV point clouds for comparison across the different strata that were over $2 \mathrm{~m}$ tall in Table 2 [22,23]. Attribute class were assigned, as described in Table 3 for the forest type map of South Korea, according to a previous study [24]. A tree height uses 3 point measurement in the forest type map. And a canopy cover density in the forest type map was determined simply by visual reading and digital stereo plotter. The 3 point method using digital stereo plotter takes the average of three tree heights from each stand (at a high, medium, and low elevation in the stand), and has a tolerance of $\pm 2.0 \mathrm{~m}$. However, researchers have highlighted that this (eye) visual reading method has a lot of uncertainty. Thus, the canopy cover density is classified into 3 (classes) as shown in Table 3. 
Table 3. Tree age, diameter at breast height, tree height and canopy cover density class definitions used in the forest type map of South Korea.

\begin{tabular}{|c|c|c|c|c|c|}
\hline Tree Age & Class & Class Definition & Diameter at Breast Height & Class & Class Definition \\
\hline $1 \mathrm{st}$ & 1 & 1 10years old & Seedling & 0 & $<6 \mathrm{~cm}$ \\
\hline 2 nd & 2 & 11 20years old & Small & 1 & $6 \sim 18 \mathrm{~cm}$ \\
\hline $3 r d$ & 3 & 21 30years old & Medium & 2 & $18 \sim 30 \mathrm{~cm}$ \\
\hline 4th & 4 & 31 40years old & Large & 3 & $>30 \mathrm{~cm}$ \\
\hline 5 th & 5 & 41 50years old & Tree Height & \multicolumn{2}{|c|}{$2 \mathrm{~m}$ interval Class rounded down } \\
\hline 6th & 6 & 51 60years old & Canopy cover density & Class & Class definition \\
\hline 7th & 7 & 61 70years old & Low & A & $50 \%$ Lower cover \\
\hline 8th & 8 & 71 80years old & Medium & $\mathrm{B}$ & $50 \% \sim 70 \%$ cover \\
\hline 9th & 9 & Upper 81 years old & High & $\mathrm{C}$ & $70 \%$ upper cover \\
\hline
\end{tabular}

\section{Results and Discussion}

\subsection{Comparison of the Standard Metrics of UAV and ALS Point Clouds}

Figure 3 a shows the tree height determined by UAV and ALS point cloud measurements, compared to field measurements for different tree species. In general, the UAV and ALS point clouds produced a similar tree height distribution. The normalized height percentile differences were $5.8 \mathrm{~m}\left(\mathrm{H}_{25}\right)$, $4.9 \mathrm{~m}\left(\mathrm{H}_{50}\right), 4.2 \mathrm{~m}\left(\mathrm{H}_{75}\right)$, and $3.9 \mathrm{~m}\left(\mathrm{H}_{95}\right)$, and the differences in $\mathrm{H}_{\max }$ and $\mathrm{H}_{\text {mean }}$ were $3.8 \mathrm{~m}$ and $5.1 \mathrm{~m}$, respectively. The tree heights calculated from the UAV measurements were $3.8 \sim 5.8 \mathrm{~m}$ greater than those computed from ALS. The higher percentile tree height difference was less than the lower percentile tree height. The UAV and ALS point clouds showed good agreement when tree height was above $10 \mathrm{~m}$, and poor agreement below $10 \mathrm{~m}$. The tree height difference above $10 \mathrm{~m}$ was $10 \mathrm{~m}\left(\mathrm{H}_{25}\right)$, $5 \mathrm{~m}\left(\mathrm{H}_{50}\right), 3.1 \mathrm{~m}\left(\mathrm{H}_{75}\right)$, and $3.0 \mathrm{~m}\left(\mathrm{H}_{95}\right)$, and $\mathrm{H}_{\max }$ and $\mathrm{H}_{\text {mean }}$ were $3.0 \mathrm{~m}$ and $7.0 \mathrm{~m}$ respectively.

(a) Tree height

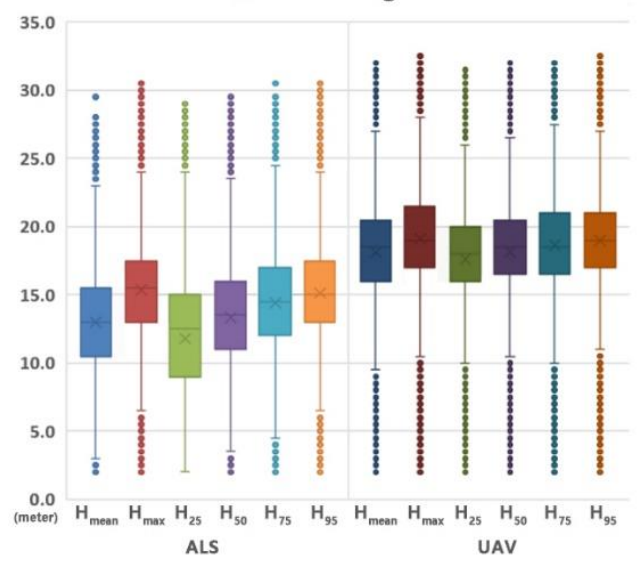

(b) Canopy cover density

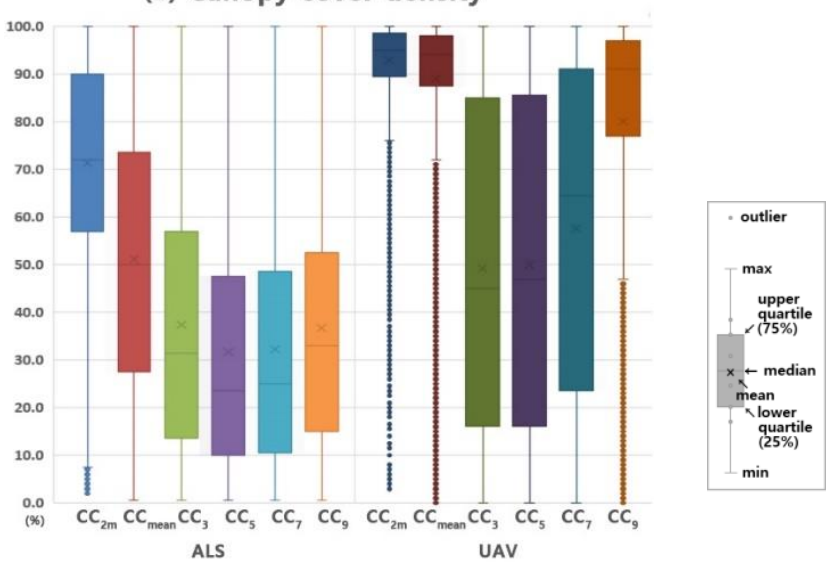

Figure 3. (a) Tree height and (b) canopy cover density statistics based on Normalized UAV and ALS point clouds ( $\mathrm{H}_{\text {mean }}, \mathrm{H}_{\text {max }}, \mathrm{H}_{25}, \mathrm{H}_{50}, \mathrm{H}_{75}, \mathrm{H}_{95}, \mathrm{CC}_{2 \mathrm{~m}}, \mathrm{CC}_{\text {mean }}, \mathrm{CC}_{3}, \mathrm{CC}_{5}, \mathrm{CC}_{7}$, and $\mathrm{CC}_{9}$ based on Table 2.).

As shown in Table 4 (refer to Table 2), the correlation between UAV and ALS measurements were $0.478\left(\mathrm{H}_{25}\right), 0.659\left(\mathrm{H}_{50}\right), 0.826\left(\mathrm{H}_{75}\right), 0.892\left(\mathrm{H}_{95},\right) 0.898\left(\mathrm{H}_{\max }\right)$, and $0.708\left(\mathrm{H}_{\text {mean }}\right)$. The higher percentiles had stronger correlations, and $\mathrm{H}_{\max }$ and $\mathrm{H}_{95}$ had a correlation greater than 0.85 . By contrast, the tree height correlation of UAV based images and TLS based LIDAR reported in a previous study $[11,25]$ was 0.89 . However, that study was conducted over a 7 month gap using 
Table 4. Correlation between tree height data determined using UAV and ALS point clouds.

\begin{tabular}{cccccccc}
\hline \multirow{2}{*}{ Tree Height Correlation } & \multicolumn{6}{c}{ UAV } \\
& $\mathbf{H}_{\mathbf{2 5}}$ & $\mathbf{H}_{\mathbf{5 0}}$ & $\mathbf{H}_{\mathbf{7 5}}$ & $\mathbf{H}_{\mathbf{9 5}}$ & $\mathbf{H}_{\text {max }}$ & $\mathbf{H}_{\text {mean }}$ \\
\hline \multirow{4}{*}{ ALS } & $\mathrm{H}_{25}$ & 0.478 & 0.527 & 0.555 & 0.551 & 0.546 & 0.535 \\
& $\mathrm{H}_{50}$ & 0.588 & 0.659 & 0.707 & 0.707 & 0.704 & 0.670 \\
& $\mathrm{H}_{75}$ & 0.674 & 0.764 & 0.826 & 0.832 & 0.830 & 0.777 \\
& $\mathrm{H}_{95}$ & 0.709 & 0.810 & 0.882 & 0.892 & 0.892 & 0.824 \\
& $\mathrm{H}_{\text {max }}$ & 0.709 & 0.812 & 0.886 & 0.898 & 0.898 & 0.826 \\
& $\mathrm{H}_{\text {mean }}$ & 0.622 & 0.696 & 0.745 & 0.745 & 0.741 & 0.708 \\
\hline
\end{tabular}

TLS whereas our study was executed over 15 months affected by seasonal differences. ALS data is susceptible to climatic conditions whereby winter negatively affects canopy cover while summer adversely impacts tree height measurements.

As shown in Figure $3 \mathrm{~b}$ and Table 5 (abbreviations based on Table 2), The $\mathrm{CC}_{3}, \mathrm{CC}_{5}, \mathrm{CC}_{7}$, and $\mathrm{CC}_{9}$ ALS calculated canopy cover density were $20 \%$ smaller than the UAV values when canopy cover density was greater than $80 \%$, and the ALS calculated canopy cover density was $30 \% \sim 50 \%$ smaller than the UAV values when canopy cover density was less than $80 \%$. The correlations for parameters $\mathrm{CC}_{3}, \mathrm{CC}_{9}, \mathrm{CC}_{\text {mean }}$, and $\mathrm{CC}_{2 \mathrm{~m}}$ were $0.246,0.208,0.324$, and 0.305 respectively, showing some agreement. But $\mathrm{CC}_{5}$ and $\mathrm{CC}_{7}$ were 0.035 and -0.02 respectively, showing no correlation and both increased for higher and lower canopy cover. Our results are similar to those of a previous study [22] that reported that correlations for ground slope and canopy cover were both less than 0.35 between UAV and ALS. The differences in canopy cover calculated using ALS and UAV point clouds are derived from the differences in the laser and optical sensors used. $\mathrm{CC}_{3}$ (canopy cover in the 25th percentile) represents low density canopy cover. Therefore, there are different sensor patterns received from the tree tops and bottoms between ALS and UAV in the $\mathrm{CC}_{3}$ zone. A comparison of ALS and UAV in Finland found that ALS values are typically greater than UAV values when canopy cover density is low [26]. The canopy cover density mean and standard deviation are greater when measurements are made using ALS. The upper percentiles show a greater difference in canopy cover density due to sensor transmission methodologies. ALS counts the number of pulses transmitted per unit time, and is used to measure from the treetops to ground level [27], whereas UAV systems only detect the treetops, producing a different result.

Table 5. Correlations between UAV and ALS canopy cover density point clouds.

\begin{tabular}{cccccccc}
\hline \multirow{2}{*}{ Canopy Cover Correlation } & \multicolumn{7}{c}{$\mathbf{U A V}$} \\
& $\mathbf{C C}_{\mathbf{2 m}}$ & $\mathbf{C C}_{\text {mean }}$ & $\mathbf{C C}_{\mathbf{3}}$ & $\mathbf{C C}_{\mathbf{5}}$ & $\mathbf{C C}_{\mathbf{7}}$ & $\mathbf{C C}_{\mathbf{9}}$ \\
\hline \multirow{4}{*}{$\mathrm{ALS}$} & 0.106 & -0.009 & 0.246 & 0.275 & 0.263 & -0.246 \\
& $\mathrm{CC}_{3}$ & 0.228 & 0.002 & -0.064 & 0.035 & 0.160 & 0.090 \\
& $\mathrm{CC}_{5}$ & 0.235 & 0.024 & -0.035 & -0.075 & -0.020 & 0.219 \\
& $\mathrm{CC}_{7}$ & 0.192 & -0.071 & -0.005 & -0.038 & -0.126 & 0.208 \\
& $\mathrm{CC}_{9}$ & 0.305 & -0.070 & -0.133 & -0.149 & 0.019 & 0.321 \\
& $\mathrm{CC}_{2 \mathrm{~m}}$ & -0.003 & 0.324 & 0.224 & 0.076 & 0.087 & -0.035 \\
\hline
\end{tabular}

AS shown in Table 5, UAV measurements have a greater point density than those taken using ALS because the UAV has a smaller GSD and image overlap, which further increases the density and may enable more accurate representation [28,29]. The horizontal accuracy of a technique is determined by the resolution and point-to-point repeatability of each datum. If two techniques have the same resolution, then horizontal accuracy is more important than GSD and resolution. If the accuracy is less than the canopy cover density of the point cloud, therefore, canopy cover density does not have a significant effect on vertical accuracy [30]. 


\subsection{Analyses of Tree Height, Diameter at Breast Height, Tree Age, and Canopy Cover Density for Fieldwork Data}

As shown in Table 6, the AH species displayed the following parameters: tree height was $15.7 \pm 1.8 \mathrm{~m}$, class 6-8; the diameter at breast height was $26.4 \pm 5.9 \mathrm{~cm}$, class $2-3$; the tree age was $40.6 \pm 3.1$ years, class 4-5; and the canopy cover was C.

Table 6. Descriptive statistics of field measurements of forest attributes.

\begin{tabular}{ccccccccccc}
\hline Fieldwork & Mean & Median & Stdev & Min & Max & Mean & Median & Stdev & Min & Max \\
\hline CC & \multicolumn{4}{c}{ AH $(\mathrm{N}=20)$ C: $100 \%$} \\
HGT & 15.7 & 15.0 & 1.8 & 13.2 & 18.8 & 14.5 & 14.4 & 2.3 & 10.3 & 21.8 \\
DBH & 26.4 & 26.0 & 5.9 & 16.0 & 42.0 & 37.2 & 39.0 & 7.9 & 22.0 & 51.0 \\
AGE & 40.6 & 41.5 & 3.1 & 32.0 & 45.0 & 61.0 & 57.0 & 11.8 & 41.0 & 87.0 \\
\hline CC & \multicolumn{9}{c}{ LL $(\mathrm{N}=30)$ C: $100 \%$} \\
HGT & 25.9 & 27.2 & 4.2 & 19.0 & 32.1 & 18.1 & 18.2 & 0.4 & 17.3 & 18.7 \\
DBH & 37.9 & 38.5 & 5.7 & 23.0 & 47.0 & 26.8 & 27.0 & 3.9 & 21.0 & 34.0 \\
AGE & 49.8 & 51.5 & 4.8 & 38.0 & 56.0 & 42.2 & 42.0 & 0.8 & 41.0 & 43.0 \\
\hline
\end{tabular}

DBH (cm: diameter at breast height), HGT: (m: Lorey's mean tree height), AGE (year: tree age), CC (canopy cover density).

The measurement for LL were: tree height equals $25.9 \pm 4.2 \mathrm{~m}$, class 10-15; the diameter at breast height equals $37.9 \pm 5.7 \mathrm{~cm}$, class 3 , the tree age equals $49.8 \pm 4.8$ years, class $4-6$, and the canopy cover was C.

On the other hand, tree height $14.5 \pm 2.3 \mathrm{~m}$, class 6-8; diameter at breast height $37.2 \pm 7.9 \mathrm{~cm}$, class 2-3; tree age $61.0 \pm 11.8$ years, class 5-8; and canopy cover as $C$ were recorded for PD.

Whereas, fieldwork results for PK included tree height $18.1 \pm 0.4 \mathrm{~mm}$ and class 8-9, diameter at breast height $26.8 \pm 3.9 \mathrm{~cm}$ and class $2-3$, tree age $42.2 \pm 0.8$ years and class 5 and the canopy cover was C.

In this study, LL demonstrated the greatest tree height, while PD showed the smallest. However, $\mathrm{PD}$ trees in the natural forest were the oldest of those measured, while AH were the youngest measured species in the artificial forest. AH had the smallest diameter at breast height, whereas PD had the largest amongst the oldest trees.

\subsection{Tree Height and Canopy Cover Density Accuracy Assessment with Fieldwork and ALS \& UAV Data by Tree Point}

The differences between tree heights calculated using ALS and those measured during fieldwork were $2.6 \mathrm{~m}(\mathrm{AH}), 1.7 \mathrm{~m}(\mathrm{LL}),-0.3 \mathrm{~m}(\mathrm{PD})$, and $-0.2 \mathrm{~m}(\mathrm{PK})$. The corresponding tree heights were about 5.1 $\mathrm{m}(\mathrm{AH}), 1.2 \mathrm{~m}(\mathrm{LL}), 0.7 \mathrm{~m}(\mathrm{PD})$, and $2.0 \mathrm{~m}(\mathrm{PK})$. The differences in height measured using the UAV and ALS were largest, in the $\mathrm{H}_{25}, \mathrm{H}_{50}$ and $\mathrm{H}_{75}$. However, $\mathrm{AH}, \mathrm{PK}, \mathrm{PD}$, and LL species were in significance level at greatest height percentiles including ALS $\mathrm{H}_{\max }$ and $A L S \mathrm{H}_{95}$ and $\mathrm{UAV} \mathrm{H}_{\max }$ and $\mathrm{H}_{95}$.

The correlation coefficients of the tree heights measured using UAV, ALS, and fieldwork were in the range $0.865-0.899$, as shown in Table 7 . The correlation between the UAV and fieldwork tree heights was between 0.72 and 0.75 [10]. The $\mathrm{H}_{\max }$ spearman correlation was $0.90-0.95$ [31]. The ALS and UAV residual standard deviation, mean, and median were in the ranges \pm 2.397 to $2.702 \mathrm{~m},-0.02$ to $2.073 \mathrm{~m}$, and -0.1 to -1.9 respectively, and ALS was better than the UAV at $\mathrm{H}_{\max }$ and $\mathrm{H}_{95}$. In two previous studies $[10,26]$, the residual standard deviations of the ALS and UAV measurements were $1.47 \mathrm{~m}$ and $2.13 \mathrm{~m}$ respectively.

We attributed the reduced standard deviation of the ALS measurements to three factors: (i) Tree height data are sensitive to seasonal changes, thus, in a previous study, ALS and UAV data collected within a single season or within 30 days had a correlation coefficients of 0.96 and 0.90 , respectively at $\mathrm{H}_{90}$, for a $1.5 \mathrm{~m}$ tree height [22]. (ii) In other studies, geolocation accuracy was reduced [11], and (iii) the sensor systems were different [25]. 
Table 7. Tree height correlation coefficients between UAV and fieldwork and ALS and fieldwork.

\begin{tabular}{|c|c|c|c|c|c|c|c|}
\hline \multirow{2}{*}{$\begin{array}{l}\text { Tree Height Fieldwork } \\
\qquad(\mathrm{N}=110)\end{array}$} & \multicolumn{3}{|c|}{$\mathrm{H}_{\max }$} & \multicolumn{4}{|c|}{$\mathrm{H}_{95}$} \\
\hline & UAV & \multicolumn{2}{|c|}{ ALS } & \multicolumn{2}{|c|}{ UAV } & \multicolumn{2}{|c|}{ ALS } \\
\hline Correlation & 0.865 & \multicolumn{2}{|c|}{0.899} & \multicolumn{2}{|c|}{0.867} & \multicolumn{2}{|c|}{0.898} \\
\hline Res. Mean/Stdev & $2.073 \pm 2.702$ & \multicolumn{2}{|c|}{$-0.020 \pm 2.397$} & \multicolumn{2}{|c|}{$1.932 \pm 2.708$} & \multicolumn{2}{|c|}{$-0.117 \pm 2.440$} \\
\hline Res. Min/Max & -4.800 & -6.500 & 7.300 & -4.900 & 9.300 & -6.700 & 7.300 \\
\hline
\end{tabular}

First order linear regressions of fieldwork, UAV, and ALS data were calculated in Table 8 and Figure 4. It is normal for no offset to be expected when a first order linear regression is performed on two datasets that are in agreement. Based on regression result, nonstandardized "B coefficients" and upper and lower bounds at $95 \%$ confidence intervals for B can be used to determine the expected range. For example, the UAV and ALS measurements are shown to be similar if the B value of their regression is close to unity. A larger value means that the values are relatively large, and a lower value means that they are relatively low.

Table 8. Zero offset linear regression for tree heights measured using UAV, ALS, and fieldwork.

\begin{tabular}{|c|c|c|c|c|c|c|c|c|c|c|c|c|}
\hline \multirow{3}{*}{$\begin{array}{c}\text { Field Work } \\
\text { By }\end{array}$} & \multicolumn{4}{|c|}{ Unstandardized Coeff. } & \multirow{2}{*}{\multicolumn{2}{|c|}{$\begin{array}{c}\text { Standard } \\
\text { Coeff. Beta }\end{array}$}} & \multirow{2}{*}{\multicolumn{2}{|c|}{$\mathbf{t}$}} & \multicolumn{4}{|c|}{$95 \%$ Confidence for B } \\
\hline & \multicolumn{2}{|c|}{ B } & \multicolumn{2}{|c|}{ Stdev } & & & & & \multicolumn{2}{|c|}{ Lower } & \multicolumn{2}{|c|}{ Upper } \\
\hline & UAV & ALS & UAV & ALS & \multicolumn{2}{|c|}{ UAV ALS } & UAV & ALS & UAV & ALS & UAV & ALS \\
\hline $\mathrm{H}_{\max }$ & 1.083 & 0.978 & 0.015 & 0.012 & 0.99 & 0.99 & 70.98 & 79.45 & 1.053 & 0.953 & 1.114 & 1.002 \\
\hline $\mathrm{H}_{95}$ & 1.076 & 0.970 & 0.015 & 0.013 & 0.99 & 0.99 & 70.72 & 77.11 & 1.046 & 0.945 & 1.106 & 0.995 \\
\hline
\end{tabular}

The $\mathrm{H}_{\max } \mathrm{B}$ determined for the ALS data was 0.978 , and the $95 \%$ confidence interval was in the range $0.953 \sim 1.002$. The average was about $2 \%$ less than the fieldwork data, suggesting that they were similar. The $\mathrm{H}_{\max }$ of $\mathrm{B}$ calculated for the UAV data was 1.083, representing an overestimation of about $8 \%$. The $95 \%$ confidence interval was in the range $1.053 \sim 1.114$. $\mathrm{H}_{95}$ was 1.076 and the $95 \%$ confidence interval was in the range 1.046 1.106, representing an overestimation of $7 \%$.

The agreement in tree height data was in the order ALS $\mathrm{H}_{\max }$, ALS $\mathrm{H}_{95}, \mathrm{UAV} \mathrm{H}_{95}$, and $\mathrm{UAV} \mathrm{H}_{\max }$. In general, UAV measurements had larger tree heights than comparable measurements made using ALS [32-34]. When the tree height measurements using UAV and ALS were compared to fieldwork using a zero offset linear regression method similar behavior was noticed.

As shown in Table 9, the canopy cover density calculated using ALS was 10\% 30\% less than comparable measurements with the UAV. For the same canopy cover density class, all UAV $\mathrm{CC}_{2 \mathrm{~m}}$ were the same, but the ALS $C_{2 m}$ and UAV CC mean were in agreement for three tree species. The ALS $\mathrm{CC}_{\text {mean }}$ only agreed for one tree species. Therefore, $\mathrm{UAV} \mathrm{CC}_{2 \mathrm{~m}}$ produced the best measurement of the forest canopy cover density.

The different techniques were assigned the following order of canopy cover density similarity: UAV $\mathrm{CC}_{2 \mathrm{~m}}$, UAV $\mathrm{CC}_{\text {mean }}$, ALS $\mathrm{CC}_{2 \mathrm{~m}}$, and ALS $\mathrm{CC}_{\text {mean }}$. The canopy cover calculated using LIDAR differed from estimates using traditional methods, such as fieldwork, or aerial and satellite imagery. The canopy cover calculated using LIDAR was overestimated in areas with a low canopy coverage (less than $30 \%$ ), but underestimated in areas with a high coverage (the upper $50 \%$ ). The mean difference in canopy cover estimates was in the range $-10 \%$ (canopy coverage $<30 \%$ ) to $-20 \%$ (upper $30 \%$ of canopy coverage data) [35]. 


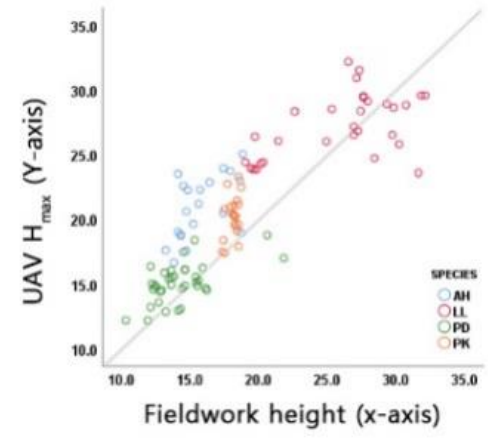

(a)

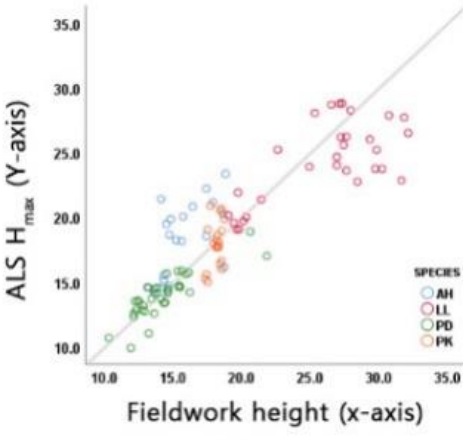

(b)

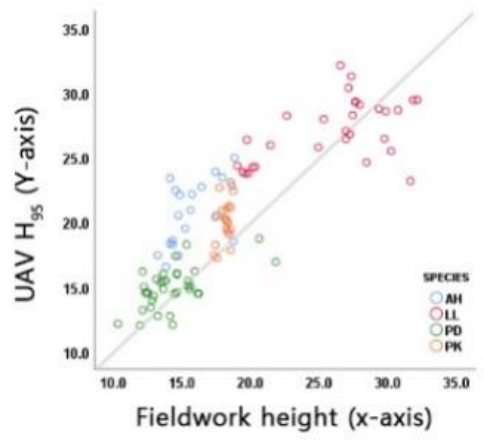

(c)

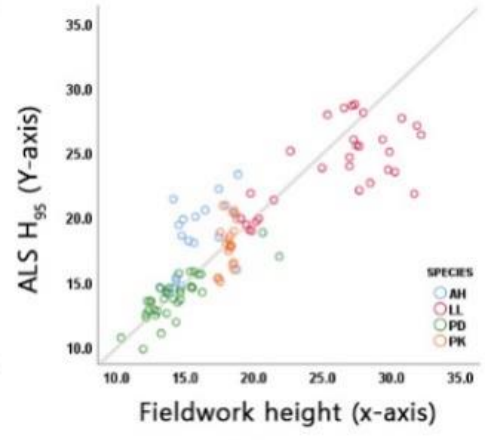

(d)

Figure 4. Scatter plot for a comparing the measured tree height using $\mathrm{H}_{\max }$ and $\mathrm{H}_{95}$ from UAV and ALS with Fieldwork result. a) Hmax-UAV; b) Hmax-ALS; c) H95 -UAV; d) H95-ALS

Table 9. Comparison of the canopy cover density $\mathrm{CC}_{2 \mathrm{~m}}$ and $\mathrm{CC}_{\text {mean }}$ calculated by fieldwork, UAV, and ALS

\begin{tabular}{|c|c|c|c|c|c|c|c|c|c|c|c|c|c|c|c|c|}
\hline \multirow{3}{*}{$\begin{array}{c}\text { Canopy Cover Density } \\
\text { (Unit: \%) } \\
\text { Field Work }\end{array}$} & \multicolumn{4}{|c|}{$\mathrm{AH}(\mathrm{N}=20)$} & \multicolumn{4}{|c|}{$\operatorname{LL}(\mathbf{N}=30)$} & \multicolumn{4}{|c|}{$\mathrm{PD}(\mathrm{N}=40)$} & \multicolumn{4}{|c|}{$\mathrm{PK}(\mathrm{N}=20)$} \\
\hline & \multicolumn{2}{|c|}{$\begin{array}{l}\text { Value } \\
>70.0\end{array}$} & \multicolumn{2}{|c|}{$\begin{array}{c}\text { Class } \\
\mathrm{C}\end{array}$} & \multicolumn{2}{|c|}{$\begin{array}{l}\text { Value } \\
>70.0\end{array}$} & \multicolumn{2}{|c|}{$\begin{array}{c}\text { Class } \\
\text { C }\end{array}$} & \multicolumn{2}{|c|}{$\begin{array}{l}\text { Value } \\
>70.0\end{array}$} & \multicolumn{2}{|c|}{$\begin{array}{c}\text { Class } \\
\text { C }\end{array}$} & \multicolumn{2}{|c|}{$\begin{array}{l}\text { Value } \\
>70.0\end{array}$} & \multicolumn{2}{|c|}{$\begin{array}{c}\text { Class } \\
\mathrm{C}\end{array}$} \\
\hline & ALS & UAV & ALS & UAV & ALS & UAV & ALS & UAV & ALS & UAV & ALS & UAV & ALS & UAV & ALS & UAV \\
\hline $\mathrm{CC}_{2 \mathrm{~m}}$ & 77.0 & 95.6 & $\mathrm{C}$ & $\mathrm{C}$ & 64.6 & 88.3 & B & $\mathrm{C}$ & 83.1 & 82.3 & $\mathrm{C}$ & $\mathrm{C}$ & 84.6 & 96.9 & $\mathrm{C}$ & $\mathrm{C}$ \\
\hline $\mathrm{CC}_{\text {mean }}$ & 62.2 & 95.6 & B & $\mathrm{C}$ & 53.5 & 86.2 & B & $\mathrm{C}$ & 27.9 & 48.2 & $\mathrm{~A}$ & B & 81.6 & 96.9 & $\mathrm{C}$ & $\mathrm{C}$ \\
\hline
\end{tabular}


3.4. Comparison of Tree Height and Canopy Cover Density Using the Forest Type Map and Fieldwork Data in Same Polygon

The greatest difference is between tree height, and the smallest difference is between canopy cover density values (Table 10). The greatest difference in tree height calculated during our fieldwork and recorded on the forest type map was between $1.5 \mathrm{~m}$ and $9.2 \mathrm{~m}$, while the greatest class difference was from 1 to 5 . The greatest difference in diameter at breast height was one class, with a difference of $13.2 \mathrm{~cm}$ to $15.0 \mathrm{~cm}$. The difference in estimated tree age was $1 \sim 3$ classes and $14.8 \sim 27$ years. The attributes recorded in the forest type map were mostly underestimated according to our fieldwork, except for canopy cover density that demonstrated a good agreement.

Table 10. Differences between the fieldwork data and the forest type map records.

\begin{tabular}{|c|c|c|c|c|c|c|c|c|c|c|c|c|}
\hline \multirow{3}{*}{$\begin{array}{l}\mathrm{Na} \\
\mathrm{me}\end{array}$} & \multicolumn{6}{|c|}{ Tree Height(m) (Class ${ }^{1)}$, Value) } & \multicolumn{6}{|c|}{ Canopy Cover Density(\%) (Class ${ }^{2)}$, Value) } \\
\hline & \multicolumn{2}{|c|}{ Fieldwork } & \multicolumn{2}{|c|}{ Map } & \multicolumn{2}{|c|}{ Diff Class } & \multicolumn{2}{|c|}{ Fieldwork } & \multicolumn{2}{|c|}{ Map } & \multicolumn{2}{|c|}{ Diff Class } \\
\hline & Class & Value & Class & Value & Class & Value & Class & Value & Class & Value & Class & Value \\
\hline $\mathrm{AH}$ & 7 & 15.7 & 5 & 11 & 2 & 14.4 & & & & & Sa & \\
\hline LL & 12 & 25.9 & 9 & 19 & 3 & 13.9 & & & & & Sa & \\
\hline PD & 7 & 14.5 & 6 & 13 & 1 & 13.2 & & & & & $\mathrm{Sa}$ & \\
\hline PK & 9 & 18.2 & 4 & 9 & 5 & 15.0 & & & & & $\mathrm{Sa}$ & \\
\hline
\end{tabular}

(1) "Value/2 and rounded down" for tree height classification on Table 3; (2) Canopy cover density classification on Table 3.

Map makers can find the height of AH and PD trees according to their base and top. Based on the forest type map that were produced using fieldwork and a digital stereo plotter, the tree height of a PD can be calculated within the tolerance of $\pm 2.0 \mathrm{~m}$, which is more accurate than LL and PK. The tree types can be ordered according to the difference in diameter at breast height as PD, LL, AH, and PK. This is similar to the order according to age: LL, PD, AH, and PK. The AH and PK studied during our fieldwork were in a valley, near a stream. Typically, trees are taller in a valley [36], so the size of AH and $\mathrm{PK}$ is expected to be overestimated.

\subsection{Tree Height and Canopy Cover Density Recorded in The Forest Type Map Against Measurements Using $U A V$ and $A L S$}

As shown in Table 11, the differences between the $\mathrm{AH}$ tree height recorded in the forest type map, and the ALS and UAV data recorded here are less than $6.2 \mathrm{~m}$ and $8.6 \mathrm{~m}$, respectively. LL measured using ALS was estimated to be less than $0.2 \mathrm{~m}$, and the UAV was about $4.3 \mathrm{~m}$. PD measured using ALS was estimated to be less than $1.7 \mathrm{~m}$ and the UAV was about $2.4 \mathrm{~m}$. PK measured using ALS was estimated to be $7 \mathrm{~m}$ while UAV was about $9.3 \mathrm{~m}$.

Table 11. Comparison of tree heights according to the forest type map and fieldwork (unit: $\mathrm{m}$ ).

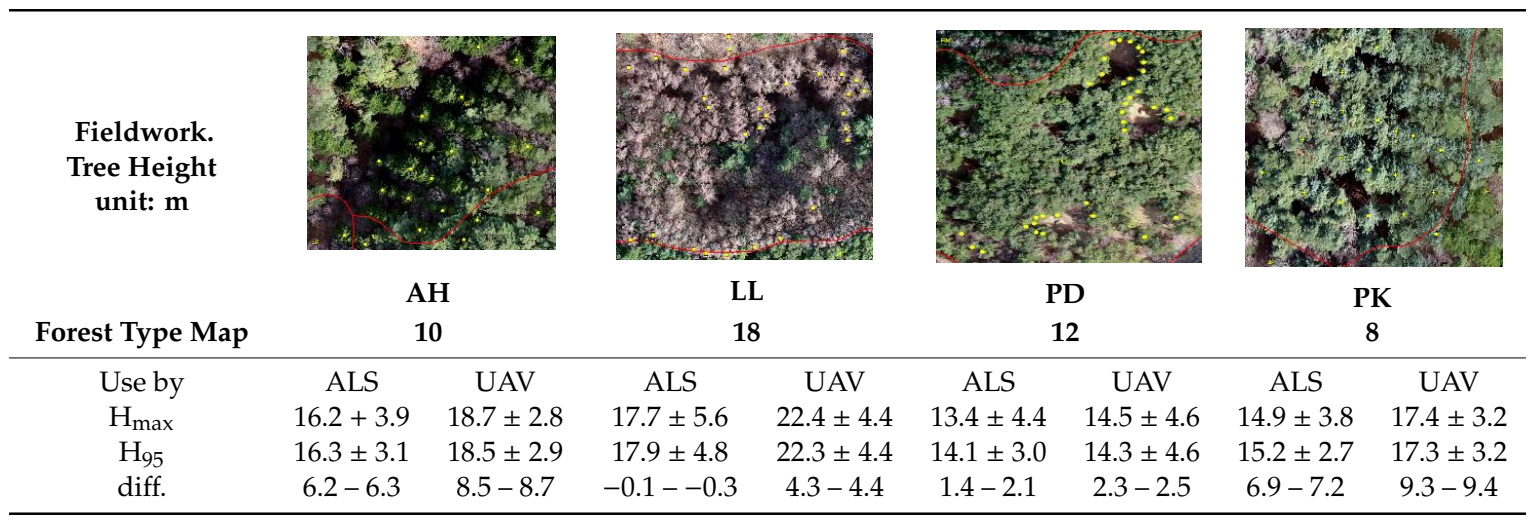


The tree height calculated using a UAV was greater than that measured with ALS. As such, the forest type map will underestimate tree heights as in Table 12. The correlation between ALS and UAV data and the forest type map tree height was inverse and between -0.286 and -0.151 . The correlations for $\mathrm{H}_{\max }, \mathrm{H}_{95}$, and $\mathrm{H}_{\text {mean }}$ between UAV and ALS measurements were in the range 0.836 0.892. These data indicated that the UAV and ALS data for tree height are rigorous, thus, insinuating a change of measurement technique for the forest type map.

Table 12. Tree height correlations among ALS, UAV, and Forest type map.

\begin{tabular}{|c|c|c|c|c|c|c|c|c|}
\hline \multirow{2}{*}{\multicolumn{2}{|c|}{ Tree Height }} & \multirow{2}{*}{$\begin{array}{c}\text { Forest Type Map } \\
\text { Tree Height }\end{array}$} & \multicolumn{3}{|c|}{ ALS } & \multicolumn{3}{|c|}{ UAV } \\
\hline & & & $\mathbf{H}_{\max }$ & $\mathrm{H}_{95}$ & $\mathbf{H}_{\text {mean }}$ & $\mathbf{H}_{\max }$ & $\mathrm{H}_{95}$ & $\mathbf{H}_{\text {mean }}$ \\
\hline $\begin{array}{r}\text { Fores } \\
\text { tre }\end{array}$ & $\begin{array}{l}\text { e map } \\
\text { ight }\end{array}$ & 1.000 & -0.199 & -0.151 & -0.286 & -0.186 & -0.189 & -0.207 \\
\hline \multirow{3}{*}{ ALS } & $\mathrm{H}_{\max }$ & -0.199 & 1.000 & 0.944 & 0.983 & 0.886 & 0.884 & 0.870 \\
\hline & $\mathrm{H}_{95}$ & -0.151 & 0.944 & 1.000 & 0.927 & 0.860 & 0.959 & 0.836 \\
\hline & $\mathrm{H}_{\text {mean }}$ & -0.286 & 0.983 & 0.927 & 1.000 & 0.892 & 0.891 & 0.886 \\
\hline \multirow{3}{*}{ UAV } & $\mathrm{H}_{\max }$ & -0.186 & 0.886 & 0.860 & 0.892 & 1.000 & 1.000 & 0.995 \\
\hline & $\mathrm{H}_{95}$ & -0.189 & 0.884 & 0.959 & 0.891 & 1.000 & 1.000 & 0.996 \\
\hline & $\mathrm{H}_{\text {mean }}$ & -0.207 & 0.870 & 0.836 & 0.886 & 0.995 & 0.996 & 1.000 \\
\hline
\end{tabular}

However, the forest type map makers used a $25 \mathrm{~cm}$ GSD aerial photograph taken by the Korean National Geographic Information Institute via the 3 point method [2]. It is difficult to identify the tops of trees and the ground level when using a GSD based photograph. Moreover, implementation of the 3 point method requires a high level of experience and skill. After verification through fieldwork, we found that the forest type map had tree height errors [37].

The tree height recorded in the forest type map would have been within $\pm 2.0 \mathrm{~m}$ tolerance if the stand was in low canopy cover density forest, or where the bottom of a tree could be easily found. But high canopy cover density areas were out of tolerance, and our fieldwork data identified many differences in tree heights. Generally, the 3 point method has been used to draw 3800 maps from digital stereo plotter. The ALS and UAV methods used here are expensive and require many man hours. It is both quicker and cheaper to measure tree height using the 3 point method, which is why it has been used by the forest type map makers.

The differences in diameter at breast height and tree age classes resulted from long distance naked eye measurements as well as problems with the interpretation of aerial photographs [24]. Excluding LIDAR, there was high confidence in the 3 point technique, and it is being used for tree height measurements by most forestry researchers.

As shown in Figure 5, the tree heights of the 84 polygons in the forest type map are underestimated between $-2.16 \mathrm{~m}$ and $-0.15 \mathrm{~m}$, with a standard deviation of $\pm 4.62 \mathrm{~m}$ and a class difference of $\pm 2 \sim 3$. The values were greater for natural forest species (EB, MM, PD, QA, QM, QQ, QV) than for artificial forest (AH, LL, PK, PO). The trees in artificial forests are planted around the same time, and thus their tree heights are constant. In contrast, natural forests grow over time, and thus, the standard deviation is relatively large. Over the years, the standard deviation and range of artificially planted PKs have largely been accurately estimated.

As shown in Table 13, the canopy cover density class consistency across 84 stands was $27.4 \%$ for ALS CC $2 \mathrm{~m}, 69.04 \%$ for UAV CC $2 \mathrm{~m}, 3.6 \%$ for $\mathrm{ALS} \mathrm{CC}_{\text {mean }}$, and $39.3 \%$ for UAV $\mathrm{CC}_{\text {mean }}$. UAV CC $2 \mathrm{~m}$ was the best while ALS $\mathrm{CC}_{\text {mean }}$ was the worst canopy cover density measurement.

Individual tree heights agreed well with field measurements [38]. And exact crown width data can be distinguished using high canopy cover density LIDAR point clouds [39]. Uncertainty factors such as artificial measurement errors and inconsistent standards often affect ground measurements of crown amplitude, which results in low accuracy CC estimations [40]. 


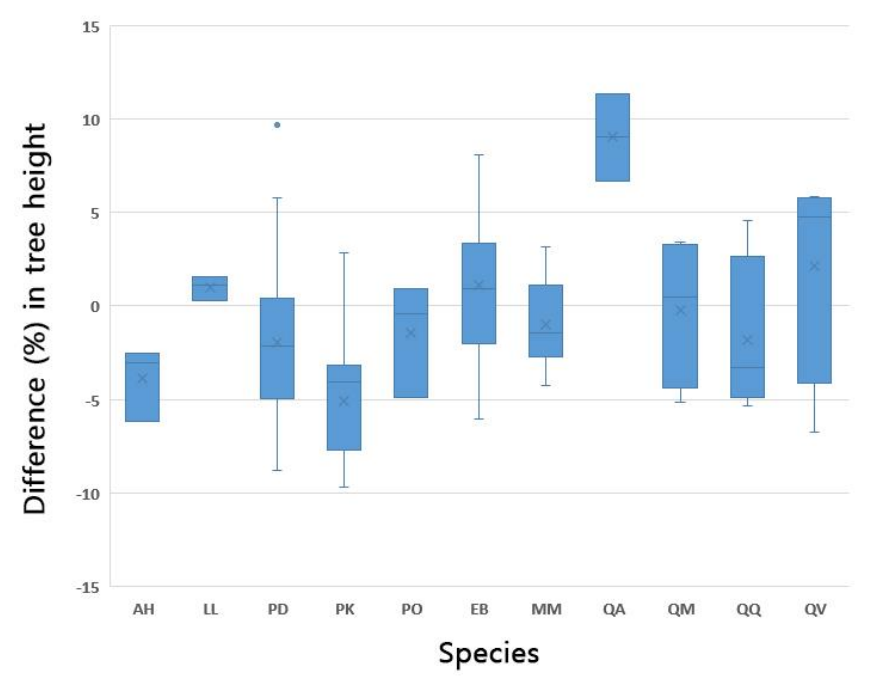

Figure 5. Differences in tree heights between tree height class and ALS $\mathrm{H}_{\max }$ according to stand. (AH: Abies holophylla, EB: Etc. broadleaf, LL: Larix kaempferi, MM: Mixed forest, PD: Pinus densiflora, PK: Pinus koraiensis, PO: Populous, QA: Quercus acutissima, QM: Quercus mongolica, QQ: Etc. Quercus, QV: Quercus variabilis).

Table 13. Differences in canopy cover density between the forest type map and ALS and UAV measurements.

\begin{tabular}{|c|c|c|c|c|c|c|c|c|c|c|c|c|c|c|}
\hline \multicolumn{3}{|c|}{ Canopy Cover Density Class } & \multicolumn{3}{|c|}{ ALS CC $2 m$} & \multicolumn{3}{|c|}{ UAV $\mathrm{CC}_{2 \mathrm{~m}}$} & \multirow[b]{2}{*}{$\mathbf{A}$} & \multicolumn{2}{|c|}{ ALS CC $C_{\text {mean }}$} & \multicolumn{3}{|c|}{ UAV $\mathrm{CC}_{\text {mean }}$} \\
\hline \multicolumn{2}{|c|}{ Class } & \multirow{2}{*}{$\begin{array}{c}\text { Counts } \\
2\end{array}$} & \multirow{2}{*}{$\frac{\mathbf{A}^{\mathbf{1})}}{1^{(\mathrm{a})}}$} & \multirow{2}{*}{$\begin{array}{l}\mathbf{B}^{1)} \\
1^{(\mathrm{b})}\end{array}$} & \multirow{2}{*}{$\frac{\mathbf{C}^{\mathbf{1})}}{0^{(\mathrm{c})}}$} & \multirow{2}{*}{$\begin{array}{c}\mathbf{A} \\
0\end{array}$} & \multirow{2}{*}{$\begin{array}{l}\text { B } \\
0\end{array}$} & \multirow{2}{*}{ C } & & \multirow{2}{*}{$\begin{array}{l}\text { B } \\
1\end{array}$} & \multirow{2}{*}{$\begin{array}{l}\text { C } \\
0\end{array}$} & \multirow{2}{*}{$\begin{array}{c}\mathbf{A} \\
1\end{array}$} & \multirow{2}{*}{$\begin{array}{l}\text { B } \\
0\end{array}$} & \multirow{2}{*}{$\begin{array}{l}\mathrm{C} \\
1\end{array}$} \\
\hline Forest & $\mathrm{A}^{2)}$ & & & & & & & & $\begin{array}{c}\mathbf{A} \\
1\end{array}$ & & & & & \\
\hline type & $\mathrm{B}^{2)}$ & 15 & $8^{(\mathrm{d})}$ & $5^{(a)}$ & $2^{(b)}$ & 2 & 2 & 11 & 13 & 2 & 0 & 6 & 3 & 6 \\
\hline map & $C^{2)}$ & 67 & $16^{(\mathrm{f})}$ & $34^{(d)}$ & $17^{(\mathrm{a})}$ & 2 & 9 & 56 & 62 & 5 & 0 & 22 & 16 & 29 \\
\hline \multicolumn{2}{|c|}{ Differences } & $\begin{array}{l}\text { (a) Same } \\
\text { (b) }-1, \text { (d) } 1 \\
\text { (c) }-2, \text { (f) } 2\end{array}$ & $\begin{array}{l}3.6^{\circ} \\
0.0^{\circ}\end{array}$ & $\begin{array}{r}27.4 \\
\%, 50.0 \\
\%, 19.0\end{array}$ & & $\begin{array}{r}13.1^{\circ} \\
2.4^{\circ}\end{array}$ & $\begin{array}{l}9.0 \\
13.1 \\
2.4^{\circ}\end{array}$ & & & $\begin{array}{l}1.2^{\circ} \\
0.0^{\circ}\end{array}$ & $\begin{array}{l}.6 \% \\
21.4 \% \\
73.8 \%\end{array}$ & & $\begin{array}{r}39.3 \% \\
7.1 \%, 26 \\
1.2 \%, 26\end{array}$ & \\
\hline
\end{tabular}

(1) Classified "A, B, C" on Table 3, (2) based on Table 2 classification.

\section{Conclusions}

In this study, a set of tree attributes were extracted which have the potential to aid us investigate better techniques amongst ALS, UAV, and fieldwork, capable of providing accurate data (standard metrics) for the improvement of the forest type map. We utilized statistical analyses to assess and derive the ALS and UAV data; validate with tree height and canopy cover data measured during the fieldwork in the Singyeri Forest of Gyeongju, and then correlated with the existent the forest type map's attributes.

This work proposes a new technique for the forest type map initially developed based on the 3 point method using digital stereo plotter that considers the average of high, medium and low tree heights from each stand; via a $25 \mathrm{~cm}$ GSD aerial photograph with a $\pm 2 \mathrm{~cm}$ tolerance.

The GSD was set to $8.95 \mathrm{~cm} /$ pixel during imaging to ascertain a consistent average point density comparable between UAV and ALS data. The digital aerial photogrammetry image processing was used to merge the UAV and ALS data; to normalize the tree height and enables the canopy cover and tree height percentiles, mean, minimum and maximum be computed.

The height measurements for UAV and ALS demonstrated stronger correlation greater than 0.85 in the higher percentiles $\left(\mathrm{H}_{95}\right.$ and $\left.\mathrm{H}_{\text {max }}\right)$ while the density parameters $\mathrm{CC}_{3}, \mathrm{CC}_{9}, \mathrm{CC}_{\text {mean }}$ and $\mathrm{CC}_{2 \mathrm{~m}}$ equals $0.246,0.208,0.324$, and 0.305 respectively displayed some agreement.

The $\mathrm{H}_{\max } \mathrm{B}$ determined for the ALS data was 0.978 , and the $95 \%$ confidence interval was in the range $0.953-1.002$. The average was about $2 \%$ less than the fieldwork data, suggesting great similarity. The $\mathrm{H}_{\max }$ of $\mathrm{B}$ calculated for the UAV data was 1.083, representing an overestimation of about $8 \%$. 
The $95 \%$ confidence interval was in the range $1.053-1.114 . \mathrm{H}_{95}$ was 1.076 and the $95 \%$ confidence interval was in the range 1.046-1.106, representing an overestimation of 7\%. However, the correlation coefficients of the tree height measured using UAV, ALS, and fieldwork in the range $0.865 \sim 0.899$ affirm that the results of this study are robust.

The tree height for the forest type map were inverse ranging from -0.286 to -0.151 while the correlation for $\mathrm{H}_{\max }, \mathrm{H}_{95}$, and $\mathrm{H}_{\text {mean }}$ between UAV and ALS ranged from 0.836 to 0.892 . The ALS calculated canopy cover was $20 \%$ smaller than UAV values when canopy cover was above $80 \%$ and when canopy cover was less than $80 \%$, ALS calculated canopy cover was 30\% to 50\% smaller than UAV values. This justifies that UAV and ALS tree height and canopy cover measurements will reliably be a better data acquisition method for the forest type map.

Note that LIDAR data is vulnerable to uncertainties in winter when evaluating canopy density because of the shaded leaves while in summer those leaves prevent a laser beam from penetrating to the tree bottom during the tree height measurement, registering inaccuracies. Additionally, it is difficult to identify the tops of trees and ground when using a GSD photograph. Thus, a tree height recorded in the forest type map could be within tolerance in case of low-density forest or accessible tree bottoms.

However, a tree height values on the forest type map are underestimated, and the measurement technique should be changed. Therefore, we suggest that forest managers adopt a mixed method whereby highest percentile. ALS $\mathrm{H}_{\max }, \mathrm{H}_{95}$ or 3 point method be used for a tree heights, UAV $\left(\mathrm{CC}_{2 \mathrm{~m}}\right)$ for a canopy cover density, and fieldwork for an age and a diameter at breast height data, to produce accurate the forest type map.

Author Contributions: Formal analysis, C.-y.O., N.W.N. and C.C.; data curation, S.S., C.J. and C.C.; writing-original draft preparation, S.S. and C.C.; writing-review and editing, C.J., N.W.N.; visualization, C.J. and C.-y.O.; supervision, C.C. All authors have read and agreed to the published version of the manuscript.

Funding: This research received no external funding.

Acknowledgments: This work was supported by the BK21 plus Project of the Graduate School of Earth Environmental Hazard System.

Conflicts of Interest: The authors declare no conflict of interest.

\section{References}

1. Korea Statistical Information Service Forest Area and Growing Stock Statics. Available online: http: //index.go.kr/potal/main/EachDtlPageDetail.do?idx_cd=1300 (accessed on 14 August 2019).

2. Kim, K.; Mun, G.; Lee, J.; Kim, C.; Lim, J. Application of Remote Sensing Data for Advancing Forest Type Map; Research Report; Korea National Institute of Forest Service: Seoul, Korea, 2016; Volume 30, ISBN 979-11-6019-030-4.

3. Hernández-Clemente, R.; Navarro-Cerrillo, R.M.; Ramírez, F.J.R.; Hornero, A.; Zarco-Tejada, P.J. A Novel Methodology to Estimate Single-Tree Biophysical Parameters from 3D Digital Imagery Compared to Aerial Laser Scanner Data. Remote Sens. 2014, 6, 11627-11648. [CrossRef]

4. Brede, B.; Lau, A.; Bartholomeus, H.M.; Kooistra, L. Comparing RIEGL RiCOPTER UAV LiDAR Derived Canopy Height and DBH with Terrestrial LiDAR. Sensors 2017, 17, 2371. [CrossRef] [PubMed]

5. Andersen, H.-E.; Reutebuch, S.E.; McGaughey, R.J. A rigorous assessment of tree height measurements obtained using airborne LIDAR and conventional field methods. Can. J. Remote Sens. 2006, 32, 355-366. [CrossRef]

6. Clark, M.L.; Clark, D.B.; Roberts, D.A. Small-footprint lidar estimation of sub-canopy elevation and tree height in a tropical rain forest landscape. Remote Sens. Environ. 2004, 91, 68-89. [CrossRef]

7. Kwak, D.-A.; Lee, W.-K.; Lee, J.-H.; Biging, G.S.; Gong, P. Detection of individual trees and estimation of tree height using LiDAR data. J. For. Res. 2007, 12, 425-434. [CrossRef]

8. Falkowski, M.J.; Smith, A.M.S.; Hudak, A.T.; Gessler, P.E.; Vierling, L.A.; Crookston, N.L. Automated estimation of individual conifer tree height and crown diameter via two-dimensional spatial wavelet analysis of lidar data. Can. J. Remote Sens. 2006, 32, 153-161. [CrossRef] 
9. Zarco-Tejada, P.J.; Diaz-Varela, R.; Angileri, V.; Loudjani, P. Tree height quantification using very high resolution imagery acquired from an unmanned aerial vehicle (UAV) and automatic 3D photo-reconstruction methods. Eur. J. Agron. 2014, 55, 89-99. [CrossRef]

10. Panagiotidis, D.; Abdollahnejad, A.; Surový, P.; Chiteculo, V. Determining tree height and crown diameter from high-resolution UAV imagery. Int. J. Remote Sens. 2017, 38, 2392-2410. [CrossRef]

11. Thiel, C.; Schmullius, C. Comparison of UAV photograph-based and airborne lidar-based point clouds over forest from a forestry application perspective. Int. J. Remote Sens. 2017, 38, 2411-2426. [CrossRef]

12. Brandtberg, T.; Warner, T.A.; Landenberger, R.E.; McGraw, J.B. Detection and analysis of individual leaf-off tree crowns in small footprint, high sampling density lidar data from the eastern deciduous forest in North America. Remote Sens. Environ. 2003, 85, 290-303. [CrossRef]

13. Persson, A.E.G.; Holmgren, J.; Soederman, U. Detecting and measuring individual trees using an airborne laser scanner. Photogramm. Eng. Remote Sens. 2002, 68, 925-932.

14. Isenburg, M. Bayes Strip Align 2.1 Software Manual. Available online: http://bayesmap.com/wp-content/ uploads/StripAlign2manual.pdf (accessed on 2 July 2019).

15. Isenburg, M. LAS File Processing Using LASTOOLS. Available online: ftp://ftp.lmic.state.mn.us/pub/data/ elevation/lidar/LAS_File_Processing_Using_LASTOOLS.pdf (accessed on 29 December 2019).

16. Shivakoti, G.; Pradhan, U.; Helmi, H. Redefining Diversity and Dynamics of Natural Resources Management in Asia, Volume 1: Sustainable Natural Resources Management in Dynamic Asia; Elsevier: Amsterdam, The Netherlands, 2016; ISBN 978-0-12-810470-5.

17. Berni, J.; Zarco-Tejada, P.J.; Suarez, L.; Fereres, E. Thermal and Narrowband Multispectral Remote Sensing for Vegetation Monitoring from an Unmanned Aerial Vehicle. IEEE Trans. Geosci. Remote Sens. 2009, 47, 722-738. [CrossRef]

18. Shervais, K.; Dietrich, J.; Lauer, I. Structure from Motion (SfM) Photogrammetry Data Exploration and Processing Manual. Available online: https://kb.unavco.org/kb/file.php?id=781 (accessed on 29 December 2019).

19. Sanz-Ablanedo, E.; Chandler, J.; Rodríguez-Pérez, J.; Ordóñez, C. Accuracy of Unmanned Aerial Vehicle (UAV) and SfM Photogrammetry Survey as a Function of the Number and Location of Ground Control Points Used. Remote Sens. 2018, 10, 1606. [CrossRef]

20. Edson, C.; Wing, M.G. Airborne Light Detection and Ranging (LiDAR) for Individual Tree Stem Location, Height, and Biomass Measurements. Remote Sens. 2011, 3, 2494-2528. [CrossRef]

21. Wallace, L.; Lucieer, A.; Watson, C.; Turner, D. Development of a UAV-LiDAR System with Application to Forest Inventory. Remote Sens. 2012, 4, 1519-1543. [CrossRef]

22. White, J.; Stepper, C.; Tompalski, P.; Coops, N.; Wulder, M. Comparing ALS and Image-Based Point Cloud Metrics and Modelled Forest Inventory Attributes in a Complex Coastal Forest Environment. Forests 2015, 6, 3704-3732. [CrossRef]

23. Cao, L.; Liu, H.; Fu, X.; Zhang, Z.; Shen, X.; Ruan, H. Comparison of UAV LiDAR and Digital Aerial Photogrammetry Point Clouds for Estimating Forest Structural Attributes in Subtropical Planted Forests. Forests 2019, 10, 145. [CrossRef]

24. Kim, K.M.; Kim, C.M.; Kim, S.M.; Jung, J.H.; Lee, S.H.; KIm, J.C.; RYU, J.H.; Shim, U.B.; Kim, J.S.; Seo, S.W.; et al. 4th Forest Type Map; Korea Forest Research Institute: Seoul, Korea, 2009; p. 8.

25. Lisein, J.; Pierrot-Deseilligny, M.; Bonnet, S.; Lejeune, P. A Photogrammetric Workflow for the Creation of a Forest Canopy Height Model from Small Unmanned Aerial System Imagery. Forests 2013, 4, 922-944. [CrossRef]

26. Vastaranta, M.; Wulder, M.; White, J.; Pekkarinen, A.; Tuominen, S.; Ginzler, C.; Kankare, V.; Holopainen, M.; Hyyppä, J.; Hyyppä, H. Airborne laser scanning and digital stereo imagery measures of forest structure: Comparative results and implications to forest mapping and inventory update. Can. J. Remote Sens. 2013, 39, 382-395. [CrossRef]

27. Suárez, J.C.; Ontiveros, C.; Smith, S.; Snape, S. Use of airborne LiDAR and aerial photography in the estimation of individual tree heights in forestry. Comput. Geosci. 2005, 31, 253-262. [CrossRef]

28. Leberl, F.; Irschara, A.; Pock, T.; Meixner, P.; Gruber, M.; Scholz, S.; Wiechert, A. Point Clouds. Photogramm. Eng. Remote Sens. 2010, 76, 1123-1134. [CrossRef]

29. Baltsavias, E.P. A comparison between photogrammetry and laser scanning. ISPRS J. Photogramm. Remote Sens. 1999, 54, 83-94. [CrossRef] 
30. Haala, N.; Hastedt, H.; Wolf, K.; Ressl, C.; Baltrusch, S. Digital Photogrammetric Camera Evaluation-Generation of Digital Elevation Models. Photogramm. Fernerkund. Geoinf. 2010, 2010, 99-115. [CrossRef] [PubMed]

31. Popescu, S.C.; Wynne, R.H.; Nelson, R.F. Estimating plot-level tree heights with lidar: Local filtering with a canopy-height based variable window size. Comput. Electron. Agric. 2002, 37, 71-95. [CrossRef]

32. Bohlin, J.; Wallerman, J.; Fransson, J.E.S. Forest variable estimation using photogrammetric matching of digital aerial images in combination with a high-resolution DEM. Scand. J. For. Res. 2012, 27, 692-699. [CrossRef]

33. Järnstedt, J.; Pekkarinen, A.; Tuominen, S.; Ginzler, C.; Holopainen, M.; Viitala, R. Forest variable estimation using a high-resolution digital surface model. ISPRS J. Photogramm. Remote Sens. 2012, 74, 78-84. [CrossRef]

34. White, J.; Wulder, M.; Vastaranta, M.; Coops, N.; Pitt, D.; Woods, M. The Utility of Image-Based Point Clouds for Forest Inventory: A Comparison with Airborne Laser Scanning. Forests 2013, 4, 518-536. [CrossRef]

35. Ma, Q.; Su, Y.; Guo, Q. Comparison of Canopy Cover Estimations from Airborne LiDAR, Aerial Imagery, and Satellite Imagery. IEEE J. Sel. Top. Appl. Earth Obs. Remote Sens. 2017, 10, 4225-4236. [CrossRef]

36. Bondarchuk, S.N. Study of the Young Growth of Main Forest-forming Coniferous Species in the Primary Forests of the Sikhote-Alin Nature Reserve. Achiev. Life Sci. 2015, 9, 37-50. [CrossRef]

37. Hwang, S.-R.; Lee, M.-J.; Lee, I.-P. Detection of Individual Trees and Estimation of Mean Tree Height using Airborne LIDAR Data. J. Korea Spat. Inf. Soc. 2012, 20, 27-38.

38. Shin, P.; Sankey, T.; Moore, M.; Thode, A. Evaluating Unmanned Aerial Vehicle Images for Estimating Forest Canopy Fuels in a Ponderosa Pine Stand. Remote Sens. 2018, 10, 1266. [CrossRef]

39. Wu, X.; Shen, X.; Cao, L.; Wang, G.; Cao, F. Assessment of Individual Tree Detection and Canopy Cover Estimation using Unmanned Aerial Vehicle based Light Detection and Ranging (UAV-LiDAR) Data in Planted Forests. Remote Sens. 2019, 11, 908. [CrossRef]

40. Korhonen, L.; Korhonen, K.; Rautiainen, M.; Stenberg, P. Estimation of forest canopy cover: A comparison of field measurement techniques. Silva Fenn. 2006, 40, 577-588. [CrossRef]

(C) 2020 by the authors. Licensee MDPI, Basel, Switzerland. This article is an open access article distributed under the terms and conditions of the Creative Commons Attribution (CC BY) license (http://creativecommons.org/licenses/by/4.0/). 